\title{
Direct interface shear tests on Dunkirk sand
}

\author{
Imane Salama ${ }^{1, *}$, Christophe Dano ${ }^{1}$ \\ ${ }^{1}$ Univ.Grenoble Alpes, CNRS, Grenoble INP, 3SR, 38000 Grenoble, France
}

\begin{abstract}
After a field test campaign conducted in Dunkirk (north of France) on open-ended steel piles aiming to study the ageing phenomenon, laboratory scale shear tests were designed to study the behaviour of the sand-steel interface. In order to carry out this laboratory investigation, the direct interface shear apparatus was used for characterizing Dunkirk sand (in dry or unsaturated conditions with about $6 \%$ water content as in the field) consolidated on initially smooth mild steel plates at different consolidation time intervals $(0,1$ and 7 days) and different consolidation stresses $(50,100,200$ and $300 \mathrm{kPa})$. The test program also included two normal boundary conditions (Constant normal load CNL and constant volume CV) so that they can be compared to the field results and determine the most approaching configuration. More, the unsaturated condition induced a corrosion of the mild steel plates, causing a layer of sand remaining glued to the plate after removing the shear box. Traces of corrosion were also observed on the lower part of the sand samples (in contact with the plate). These observations lead to the interpretation of an increase of the mechanical properties (local cohesion and increase of the friction angle). In order to follow the evolution of the corrosion for each plate, thickness measurements of the sand layer stuck on the plates were carried out.
\end{abstract}

\section{Introduction}

In order to investigate the effect of time on the tension capacity of micropiles driven in Dunkirk sand (a fine and uniform sand), a series of pull-out tests were conducted, and the conclusions reported in [1]. Some of the micropiles ( $2 \mathrm{~m}$ long, about $50 \mathrm{~mm}$ in diameter) tested in Dunkirk are made of mild steel. These micropiles, contrary to stainless steel micropiles, have shown an increase in tensile capacity over time as shown in Figure 1. Field observations after complete extraction of the micropiles also revealed that sand remained attached to the pile, mainly at the toe where stress levels are more important. In order to explain this increase of capacity, a series of direct interface shear tests were designed with mild steel plates and Dunkirk sand, with two different normal boundary conditions: Constant Normal Load (CNL) or Constant Volume (CV). The CNL and CV tests were conducted at different time intervals $(0,1$ and 7 days), different constant normal stresses (50, 100, 200 and $300 \mathrm{kPa}$ ) predicted from field CPT results (Figure 2) and reproducing the radial effective stress around the micropiles at different depths. The sand used for the laboratory tests was collected in the site. The tests were also conducted on dry and unsaturated sand specimen $(6 \%$ water content as in the field).

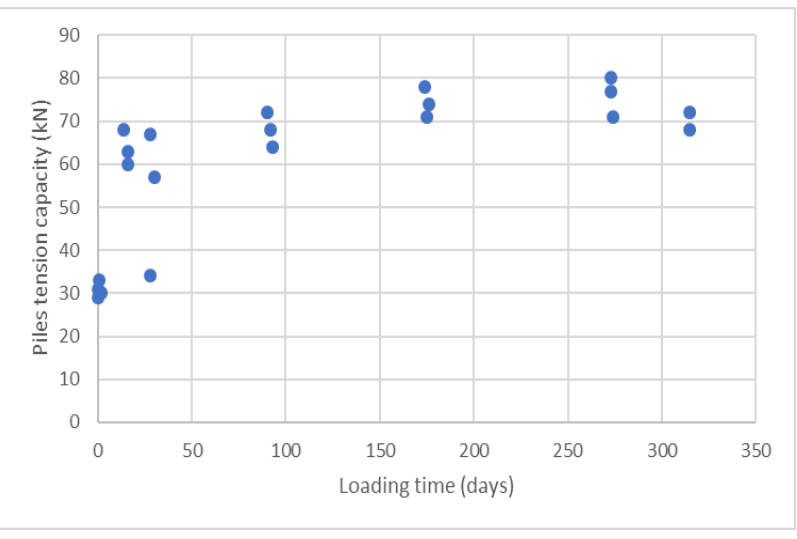

Fig. 1. Piles tension capacities.

\subsection{Sand characteristics}

The test site, located route du Grand Colombier in Gravelines (France), is relatively well-documented since many research projects were carried out in the region in the last decades (see, for instance [2]). The soil layer of interest consists of a dense to very dense marine hydraulic sand fill placed in the early 1970 s, about 3 meters deep.

Dunkirk sand, a fine and uniform material, is composed of rounded to sub-rounded particles, with a mineralogical content of about $85 \%$ of silica [3] and about $5 \%$ of shell fragments. Note that the particles larger than $1 \mathrm{~mm}$, mainly composed of shell fragments and representing $4 \%$ of the sand mass, were removed for the laboratory

\footnotetext{
* Corresponding author: imane.salama $@, 3$ sr-grenoble.fr
} 
campaign. A summary of the geotechnical properties is presented in Table 1. Note that water contents, regularly measured at a depth of 1 meter, were relatively constant, between 5 to $7 \%$, corresponding to degrees of saturation between 25 to $40 \%$. The water table was detected at a depth larger than 4 meters below ground level (BGL), well below the pile tip. Note that the tests performed in laboratory were done under the same density as in the field.

Table 1. Dunkirk soil parameters and ground conditions

\begin{tabular}{|c|c|c|}
\hline $\begin{array}{c}\text { Water table } \\
\text { BGL }\end{array}$ & Unit & Parameters \\
\hline Density & $\mathrm{m}-4.7$ \\
\hline $\begin{array}{c}\text { Origin of the } \\
\text { sand }\end{array}$ & $\begin{array}{c}\text { dense to } \\
\text { very dense }\end{array}$ \\
\hline $\begin{array}{c}\text { marine } \\
\text { hydraulic } \\
\text { fill }\end{array}$ \\
weight $\left(\gamma_{\mathrm{d}}\right)$ & $\mathrm{kN} / \mathrm{m} 3$ & 17.5 \\
\hline Water content & $\%$ & $5-7$ \\
\hline $\mathrm{Sr}$ & $\%$ & $25-40$ \\
\hline $\mathrm{D}_{50}$ & $\mathrm{~mm}$ & 0.26 \\
\hline $\mathrm{Cu}_{\mathrm{u}}$ & - & 1.7 \\
\hline \multicolumn{2}{|c}{} \\
\hline
\end{tabular}

Penetrometer tests were also performed to characterize the sand layer. Cone resistance $\mathrm{q}_{\mathrm{c}}$ from CPT and dynamic tip resistance $\mathrm{q}_{d}$ from Panda2 ${ }^{\circledR}$ presented relatively consistent values. Cone or tip resistances increase almost linearly from 0 to $20-25 \mathrm{MPa}$ at a depth of 1 meter, reach values between 30 to $40 \mathrm{MPa}$ at 1.5 meter, finally decrease up to a value of about $20 \mathrm{MPa}$ at 2 meters corresponding to the embedded depth of the micropiles (Figure 2, where Panda2 $\AA$ results are compared to the closest CPT SE test of the PISA project). Variability mainly occurs between 1 and 2 meters.

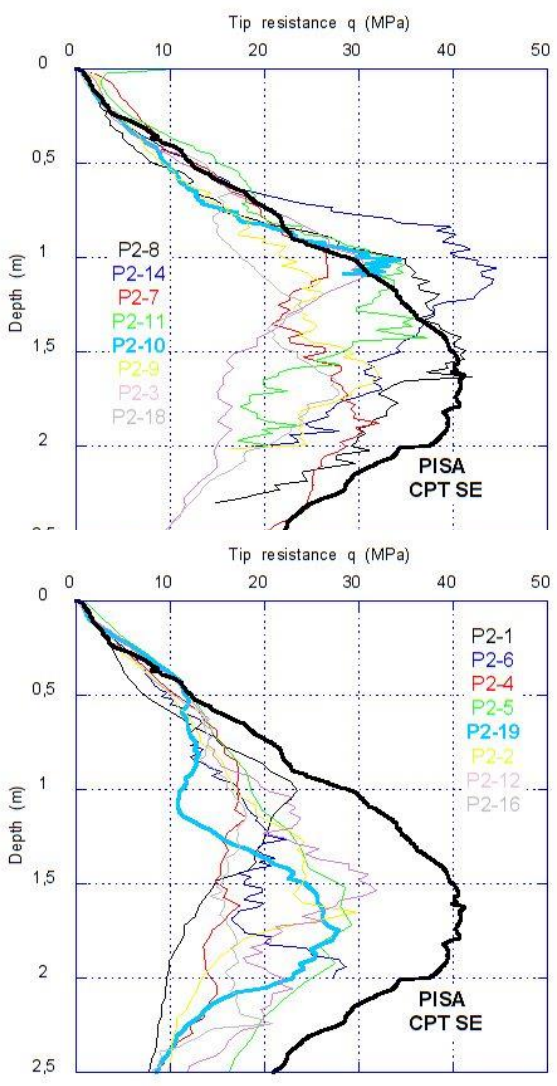

Fig. 2. Penetrometer test results.

\subsection{Analogy between the localised shear on the pile shaft and the direct interface shear apparatus}

As shown in Figure 3, during the pull-out test, a shearing occurs at the interface between the pile shaft and the soil. If we zoom in this interface zone, we can observe that the soil is submitted to a radial effective stress $\sigma^{\prime}{ }_{h}$ which value depends on the driving process and the subsequent mechanical loading, and a local free-field vertical effective stress $\sigma^{\prime}{ }_{\mathrm{v} 0}$. By analogy, in the direct shear machine, the normal stress to the interface represents this radial effective stress.

In the field, micropiles initially smooth (roughness $\mathrm{R}_{\mathrm{CLA}}$ less than $3 \mu \mathrm{m}$ ) were driven. To reproduce this configuration, smooth fresh mild steel plates were used in laboratory experiments. 


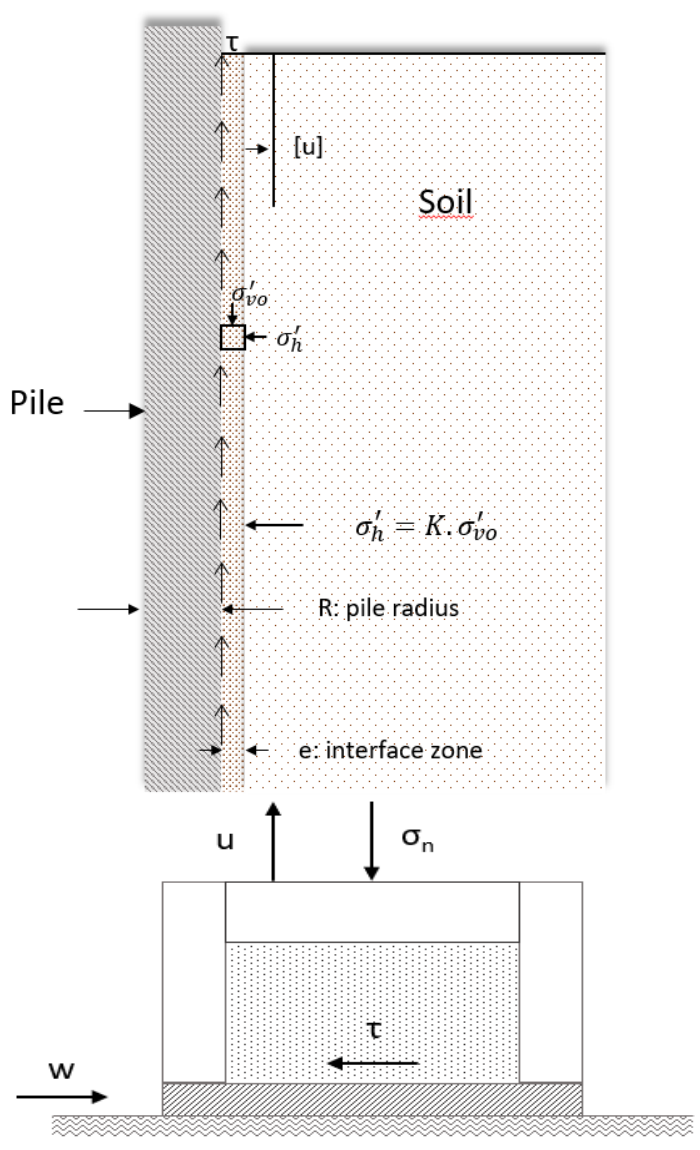

Fig. 3. Analogy between the localized shear along pile and a direct shear test, after Boulon \& Foray [1986]

\subsubsection{Constant normal load levels}

Constant Normal Load tests are currently carried out to identify the failure envelope, assuming a MohrCoulomb perfect plasticity criterion. In order to have an idea about the range of radial effective stresses in the field, we used the CPT tests results shown in Figure 2 and equations $1 \& 2$ given by [4] for open-ended piles.

$$
\begin{aligned}
\sigma_{\mathrm{rc}} & =0.029 q_{\mathrm{c}}\left(\sigma^{\prime}{ }_{\mathrm{v} 0} / \mathrm{Pa}\right)^{0.13}\left(\mathrm{~h} / \mathrm{R}^{*}\right)^{-0.38} \\
R^{*} & =\left(R_{\text {outer }}^{2}-R^{2}{ }_{\text {inner }}\right)^{0.5}
\end{aligned}
$$

where $\mathrm{h}$ is the relative depth to the tip.

From the results presented in Figure 4 showing the estimation of the field radial effective stress, we decided to choose four levels of normal stress loads for the CNL tests: 50, 100, 200 and $300 \mathrm{kPa}$.

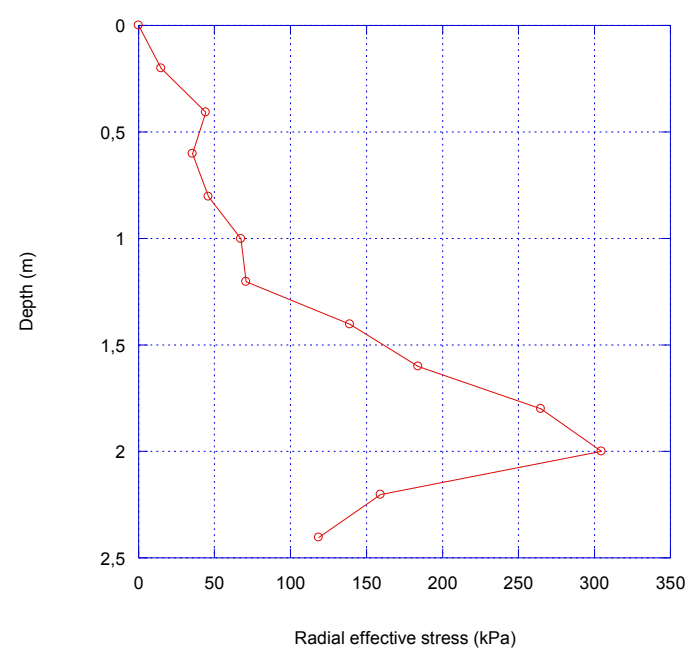

Fig. 4. Radial effective stresses from Panda2 ${ }^{\circledR}$ tests.

\subsubsection{Constant volume condition}

Assuming that the normal displacement during pullout tests induced very small normal strains to the shaft, the maximum Young's modulus for Dunkirk sand at the same density than in the field was experimentally determined at three stress levels $(150,300$ and $500 \mathrm{kPa})$ by [5], as shown in Table 2 . These values give a stiffness modulus for the soil ranging from around 170 to $330 \mathrm{MPa}$. Based on Equation 3, which takes into account the pile radius [6-7], we observe that the values of the estimated normal interface stiffness $\mathrm{K}_{\mathrm{CNS}}$ of the soil exceeds 10000 $\mathrm{kPa} / \mathrm{mm}$. From this observation, we can conclude that the test can be done under constant volume (CV) conditions.

$$
K_{C N S}=2 G / R
$$

with R: pile radius.

Table 2. Maximum vertical Young's modulus from $\mathrm{K}_{0}$ drained tests on NC samples, after [5]

\begin{tabular}{|c|c|c|c|}
\hline Sample & $E_{v}^{\prime}(\mathrm{MPa})$ & $\mathrm{G}(\mathrm{MPa})$ & $\begin{array}{c}\mathrm{K}_{\mathrm{CNS}} \\
(\mathrm{MPa} / \mathrm{mm})\end{array}$ \\
\hline DNK150C & 430 & 172 & 13.76 \\
\hline DNK300C & 640 & 256 & 20.48 \\
\hline DNK500C & 820 & 328 & 26.25 \\
\hline
\end{tabular}

\section{Experimental results}

\subsection{CNL tests}

The shearing program is composed of a first stage of shear displacement between 0 and $-2 \mathrm{~mm}$, at a displacement rate of $0.1 \mathrm{~mm} / \mathrm{min}$ (constant for all the tests). Then the displacement is reversed from $-2 \mathrm{~mm}$ to 2 $\mathrm{mm}$, before a last stage from $2 \mathrm{~mm}$ to $0 \mathrm{~mm}$. The results of the CNL tests performed on dry Dunkirk sand at four 
different levels of consolidation and at 0 day are presented in Figure 5. The cohesion C' was zero and the sand/steel interface friction angle $\delta$ was about $23^{\circ}$.
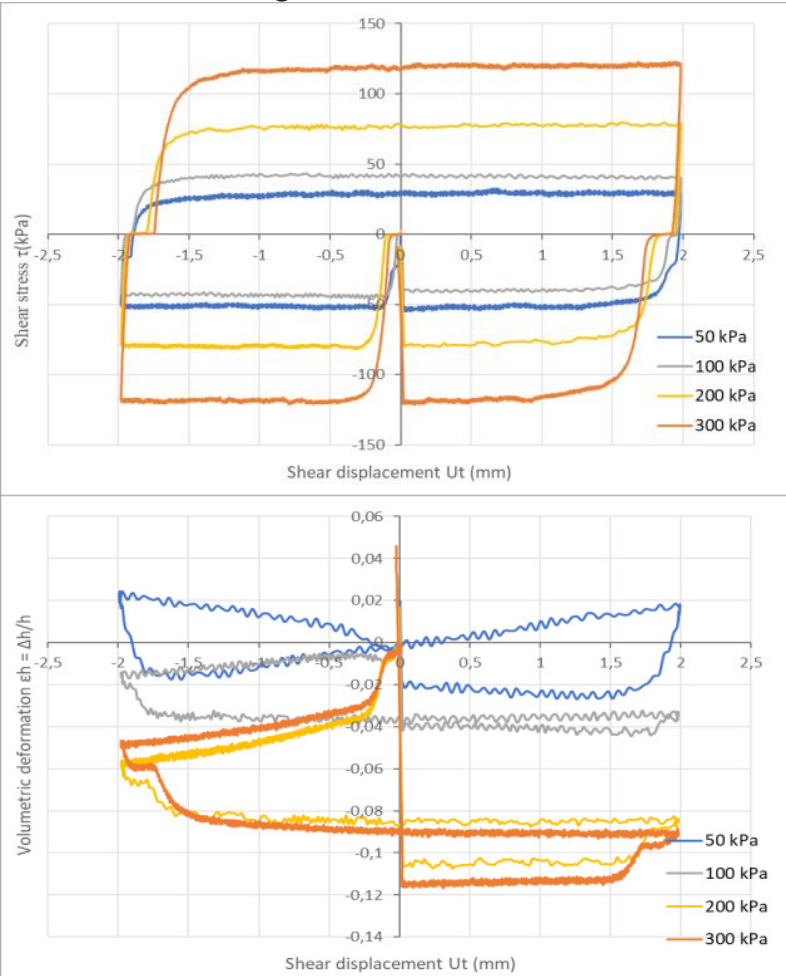

Fig. 5. CNL tests performed on dry Dunkirk sand after 0 day.

When the CNL tests conducted on dry sand at $50 \mathrm{kPa}$ after 0,1 and 7 days are compared, we notice that we have almost the same shear stress for all these 3 tests $(\sim 25 \mathrm{kPa})$ as shown in Figure 6.
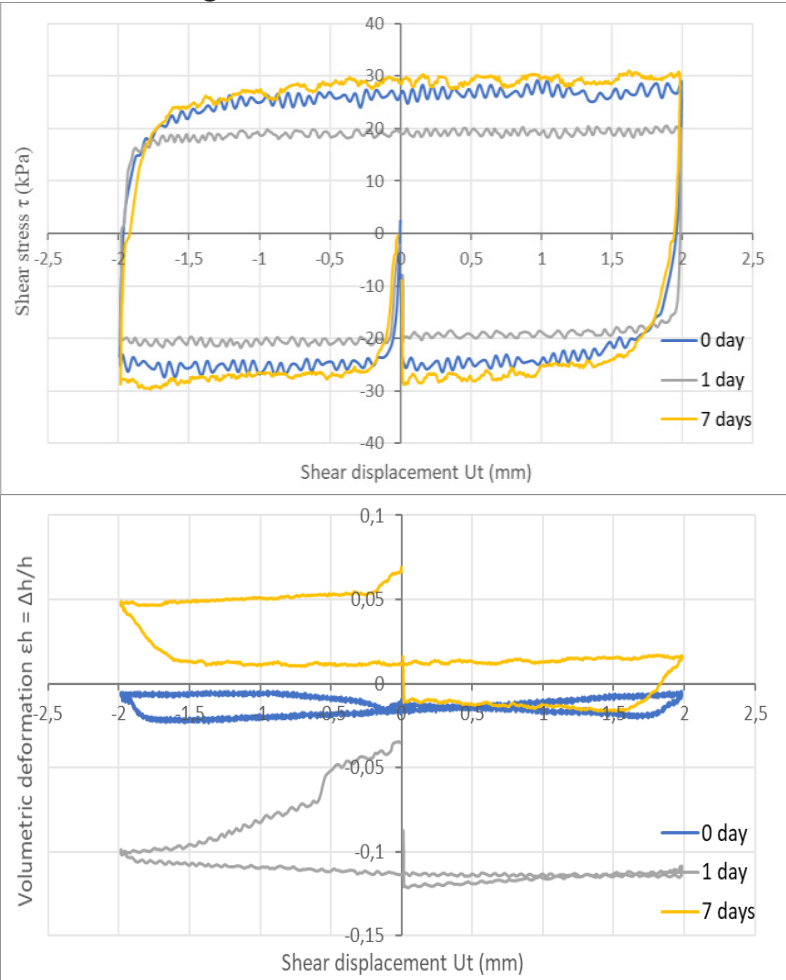

Fig. 6. CNL tests performed on dry Dunkirk sand with a normal load of $50 \mathrm{kPa}$ after 0,1 and 7 days.
With respect to the shear stresses supported by the dry sand during CNL tests at $50 \mathrm{kPa}$ for the three different intervals of time, the shear stress in similar conditions except that the sand is now in unsaturated conditions (Figure 7), represent the double $(\sim 55 \mathrm{kPa})$ with an increase in the shear stress of the unsaturated sand test of about $20 \mathrm{kPa}$ from 0 to 7 days.

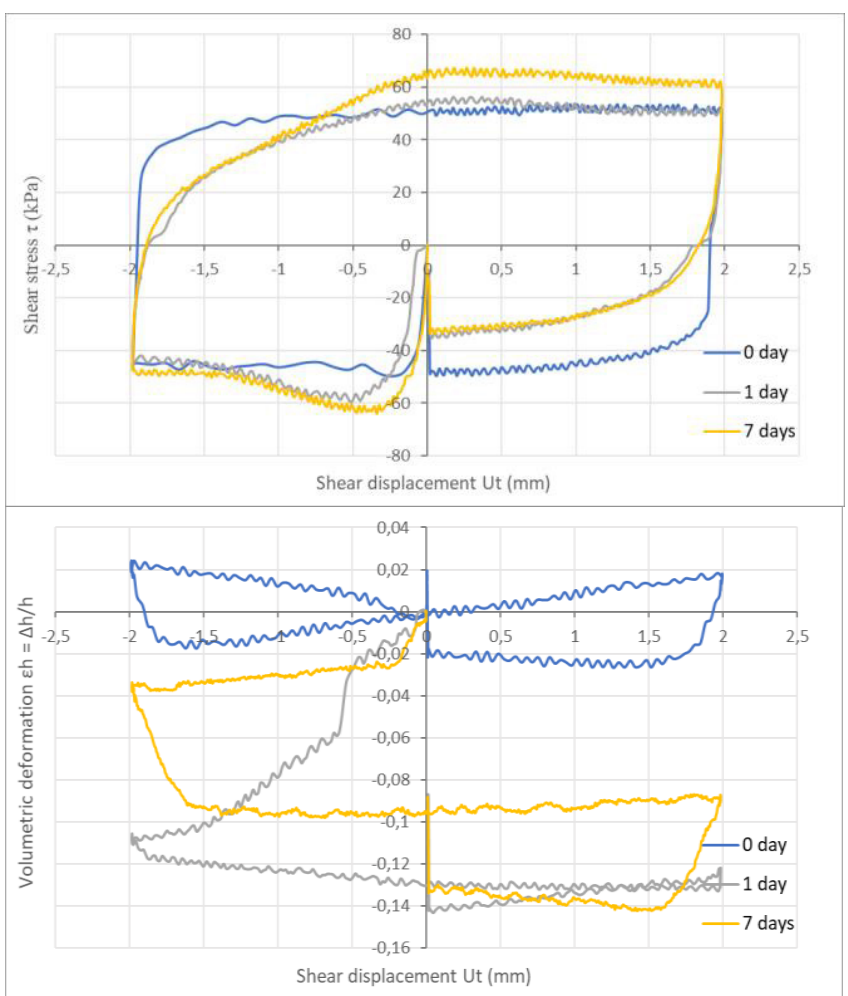

Fig. 7. CNL tests performed on unsaturated Dunkirk sand $(6 \%$ water content) with a normal load of $50 \mathrm{kPa}$ after 0,1 and 7 days.

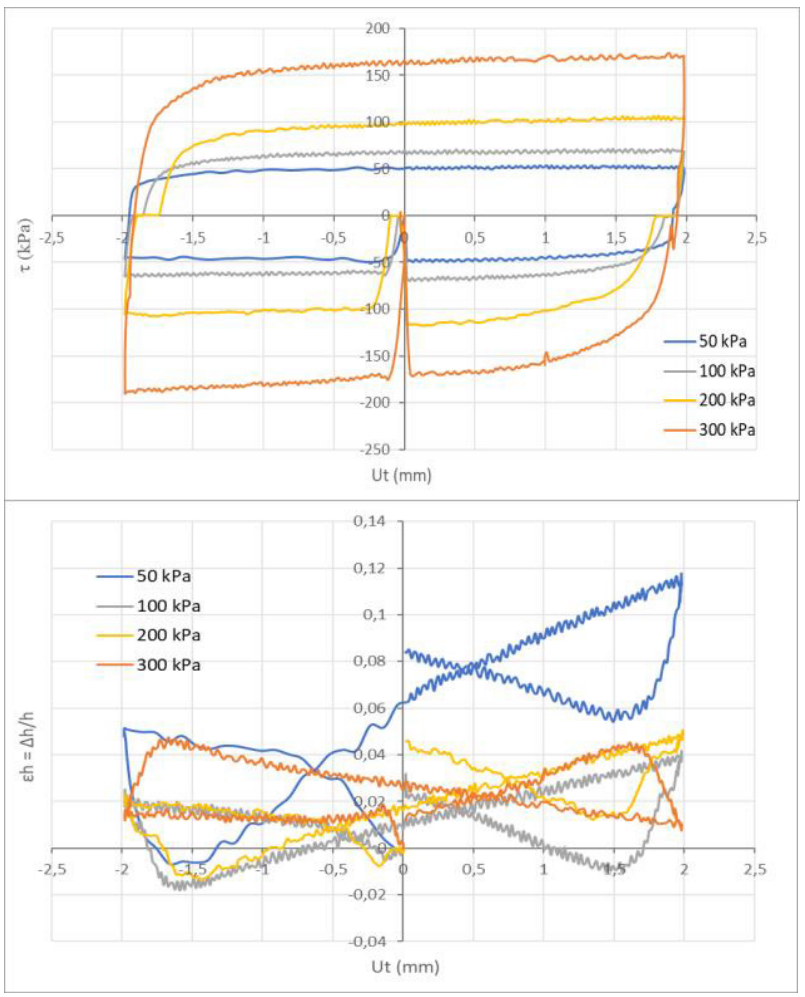


Fig. 8. CNL tests performed on unsaturated Dunkirk sand $(6 \%$ water content) after 0 day.

It was also noted that the behaviour of the dry sand was completely contracting during the shear test (Figures 5 and 6), because of the smooth nature of the steel plate, in spite of the high density of the sand. On the other hand, the unsaturated sand shows a contracting behaviour of 0 to $-0.5 \mathrm{~mm}$, then dilating from -0.5 to $-2 \mathrm{~mm}$ (Figures 7 and 8 ). The trend is reversed later for a contractancy from -2 to $-0.5 \mathrm{~mm}$ and dilatancy between -0.5 and $2 \mathrm{~mm}$. The return to 0 is in contractancy.

\subsection{CV tests}

The shear path for the constant volume tests was exactly the same as for the constant normal load tests. After consolidation $(50,100,200$ and $300 \mathrm{kPa})$ the volume was set, and the shear launched.

If the increase in shear stress is a common feature between Constant Normal Stiffness (CNS, in which $\mathrm{K}_{\mathrm{CNS}}$ is maintained constant, as defined in Eq. 3) and CV tests, it should be noted that normal stress drops significantly during the CV tests as shown in figure 9, until the failure line defined by CNL tests is reached. Depending on the shear displacement amplitude, some hardening of the interface can be retrieved for large shear displacements.

Figure 10 illustrates the Coulomb Mohr criterion for the CNS and CV tests. Note that the curves of the CV tests remain more or less in the envelope of the intrinsic curve with larger shear stress values in the first shear path (0 to $-2 \mathrm{~mm}$ ) than in the other two as shown in Figure 9.

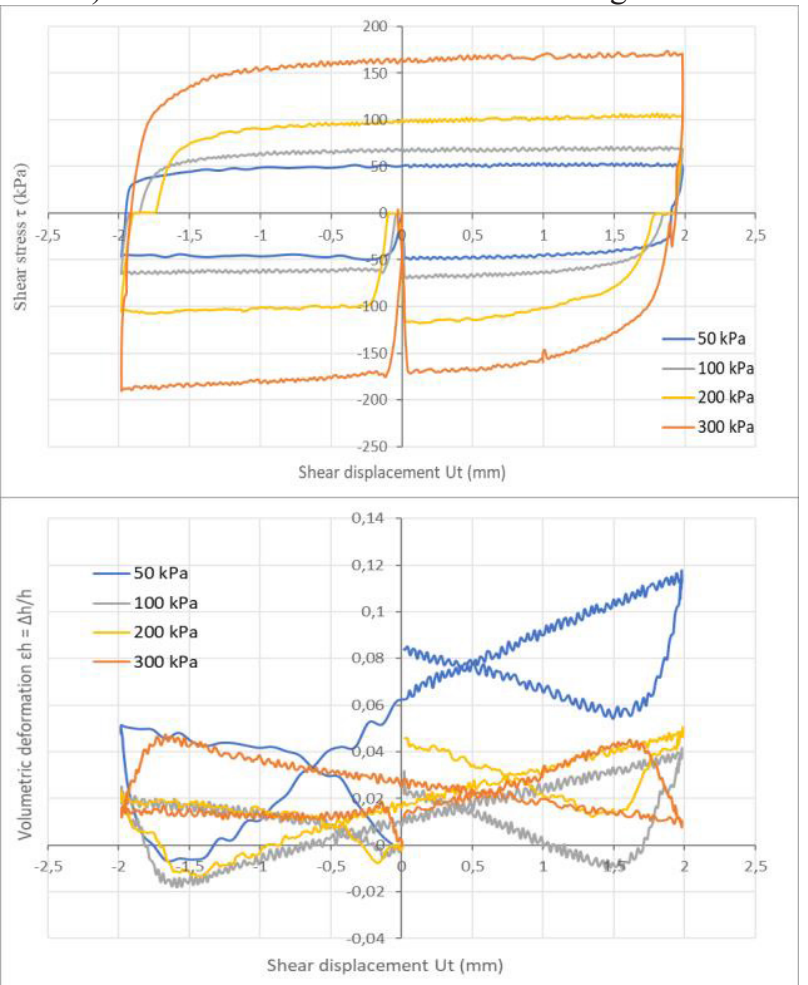

Fig. 9. CV tests performed on dry Dunkirk sand after 0 day.

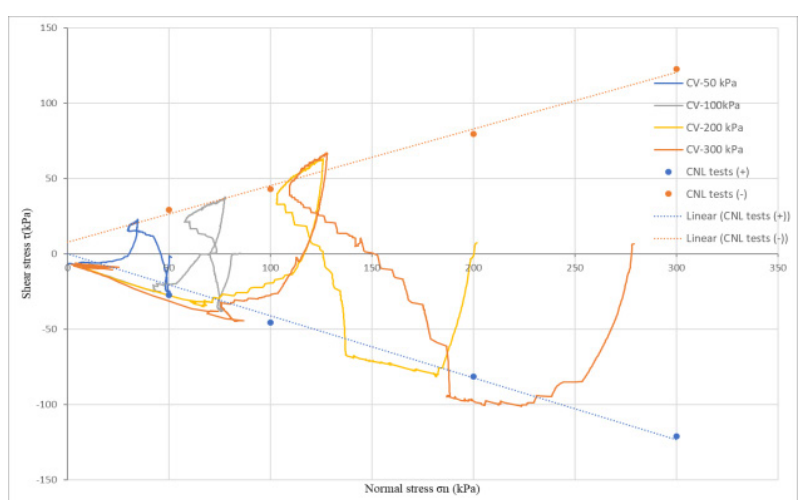

Fig. 10. Mohr-Coulomb graph for CNL and CV tests on dry sand.

\subsection{Morphology of the plates}

In order to follow and quantify the evolution of the crust on the mild steel plates, measurements on the surface were performed. These measurements give an idea about the thickness of the sand layer.

Figure 11 shows the glued sand measurement on two mild steel plates after a $50 \mathrm{kPa}$ and a $200 \mathrm{kPa}$ unsaturated sand tests. It appears that there is more sand glued on the plate submitted to the $200 \mathrm{kPa}$ test that the one submitted to the $50 \mathrm{kPa}$ test. However, the maximum height of the sand layer is almost the same for both plates $(\sim 1.5 \mathrm{~mm})$.
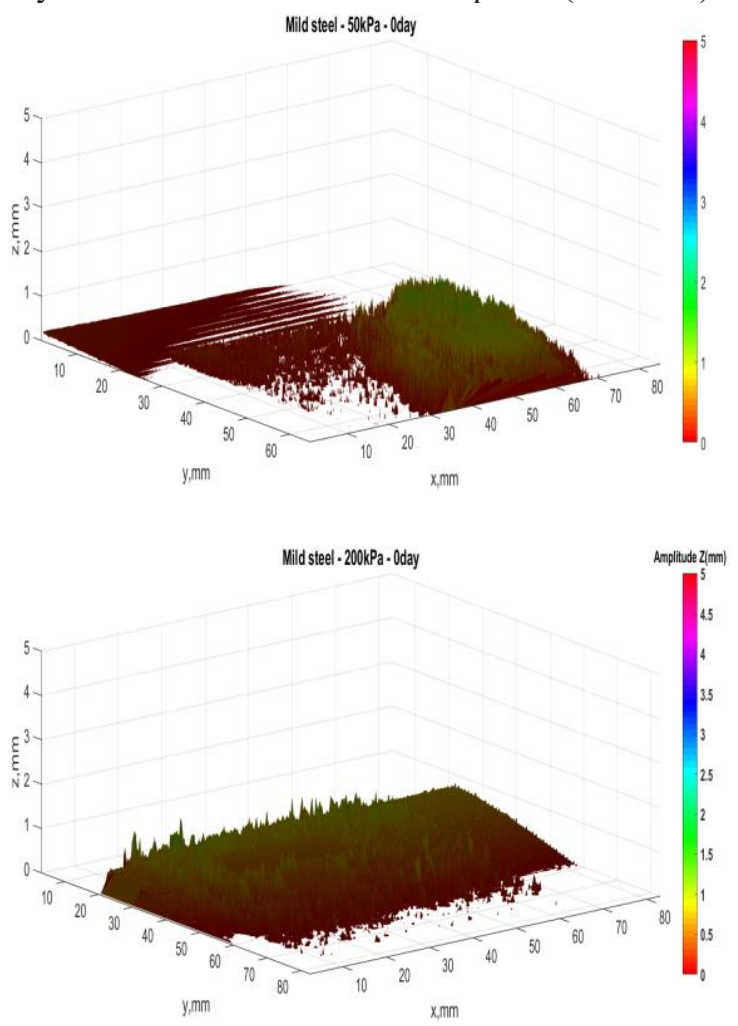

Fig. 11. Morphology of mild steel plates after CNL tests at 50 and $200 \mathrm{kPa}$ with unsaturated Dunkirk sand.

\section{Conclusions}

From the tests done so far, we can conclude that the more the normal stress is increased (and therefore the effective radial stress in situ) the more the shear stress will 
increase, and those whether in dry or unsaturated conditions. Moreover, if the shear stress showed only a slight change for dry sand tests at the same level of normal stress $(50 \mathrm{kPa})$, an increase of approximately $20 \mathrm{kPa}$ was observed for the same tests made with unsaturated sand from 0 to 7 days.

On the other hand, the volumetric deformation of the sand under the CNL tests depends on its saturation degree. Indeed, the dry sand had a completely contrancting behaviour, while the unsaturated sand showed both contractancy and dilatancy.

Regarding the CV tests we only observed the behaviour of dry sand at 0 days. It has been shown that the increase of shear stress is a common feature with CNS tests at the same conditions.

Finally, from the measurement of the sand layer height done on mild steel plates after unsaturated tests with 50 $\mathrm{kPa}$ and $200 \mathrm{kPa}$ normal load, we observed a larger amount of sand on the $200 \mathrm{kPa}$ plate than the $50 \mathrm{kPa}$ one. However, the maximum height of sand is almost the same (to be confirmed with the other plates).

\section{References}

1. R.A. Carroll, P. Carotenuto, C. Dano, I. Salama, M. Silva, K. Gavin, and R. Jardine, Field experiments at three sites to investigate the effects of age on steel piles driven in sand, (Accepted for publication in Geotechnique 2018).

2. R. Jardine and J. Standing, Field axial cyclic loading experiments on piles driven in sand. (Soils and Foundations, Vol. 52, n4, pp. 723-736. 2012).

3. F. Chow, Investigations into displacement pile behaviour for offshore foundations, (Ph.D. thesis, Department of Soil Mechanics, Imperial College, London, UK. 1997)

4. R. Jardine, F. Chow, R. Overy, J. Standing, ICP design methods for driven piles in sands and clays, Imperial College London (Book, 2005)

5. A. Aghakouchak, Advanced laboratory studies to explore the axial cyclic behaviour of driven piles, (Ph.D. thesis, Department of Soil Mechanics, Imperial College, London, UK. 2015)

6. I. W. Johnston, T. S. K Lam, \& A. F. Williams, Constant normal stiffness direct shear testing for socketed pile design in weak rock. (Géotechnique, 37(1), 83-89, 1987).

7. M. Boulon, and P. Foray, Physical and numerical simulation of lateral shaft friction along offshore piles in sand, (In Proceedings of the 3rd International Conference on Numerical Methods in Offshore Piling, Nantes, France. pp. 127-147. 1986) 